\title{
Ethnicity and Fatigue: Expressions of Distress, Causal Attributions and Coping
}

\author{
Kamaldeep S. Bhui ${ }^{1 *}$, Sokratis Dinos ${ }^{1}$, Marie-Laure Morelli ${ }^{1}$, \\ Bernadette Khoshaba ${ }^{2}$, James Nazroo ${ }^{3}$, Simon Wessely ${ }^{4}$, Peter D. White ${ }^{1}$ \\ ${ }^{1}$ Centre for Psychiatry, Barts and the London School of Medicine and Dentistry, \\ Queen Mary University of London, London, UK; \\ ${ }^{2}$ Faculty of Public Health and Policy, Department of Health Services Research and Policy, \\ London School of Hygiene \& Tropical Medicine, London, UK: \\ ${ }^{3}$ School of Social Sciences, University of Manchester, Manchester, UK; \\ ${ }^{4}$ Department of Psychological Medicine and Psychiatry, Institute of Psychiatry, \\ King's College, London, UK. \\ Email: "k.s.bhui@qmul.ac.uk \\ Received June 25 ${ }^{\text {th }}$, 2011; revised August $3^{\text {rd }}$, 2011; accepted September $11^{\text {th }}, 2011$.
}

\begin{abstract}
This paper reports on an MRC funded study of chronic fatigue and ethnicity. The purpose of the qualitative component was to compare expressions of fatigue, illness attribution, coping styles and help seeking behaviour across ethnic groups. The study used secondary analysis of qualitative data that were collected as part of the Ethnic Minority Psychiatric Illness Rates in the Community (EMPIRIC) study. The charts of the qualitative data used in the original study and the original transcripts were used to identify reports of fatigue and related symptoms that included feeling tired, exhausted, shattered, lack of energy, lack of sleep, insomnia and impaired concentration. We described symptoms by ethnic group, and examined whether ethnicity influenced illness attributions, coping strategies and help seeking behaviour. Fatigue related symptoms were common and encountered in all the ethnic groups studied, and descriptions of fatigue, illness attribution and help seeking, on the whole, did not vary between ethnic groups. The paper sets out the subtle differences between ethnic groups, and considers the use of secondary qualitative data analysis in research. Fatigue was more common among women; coping included self-help, and seeking help from social and counselling services. Religion was used as a coping mechanism mainly amongst the Pakistani, Indian and Bangladeshi ethnic groups.
\end{abstract}

Keywords: Fatigue, Ethnicity, Secondary Analysis, Qualitative

\section{Introduction}

Fatigue is one of the most common and disabling symptoms encountered in medical practice and in the population (Skapinakis, et al., 2003; Williamson et al., 2005). The population prevalence of fatigue may be as high as 30\% (Reyes-Gibby, et al., 2003). Fatigue is a feature of numerous medical and psychiatric illnesses (Addington, et al., 2001) but nevertheless remains poorly understood (Mears et al., 2004). It is a subjective symptom that encompasses emotional, cognitive and physical components (Kralik, et al., 2005), and is difficult to define and measure (Chalder, et al., 1993).

Of the few epidemiological studies that have explored the relationship between ethnicity and fatigue (Song, et al., 2002), most find no ethnic differences in prevalence (Dinos et al., 2009). However, ethnicity has been shown to moderate fatigue severity and coping strategies (Dinos, et al., 2009). For example, population-based studies have found that African Americans reported greater levels of fatigue and particularly physical, as opposed to mental, fatigue (Reyes-Gibby, et al., 2003; Bardwell, et al., 2006; Thomas, et al., 2006). A study of fatigue in primary care across 14 countries also showed that subjects from low income countries were more likely to present to their doctors with fatigue (Skapinakis, et al., 2003). Fatigue may therefore be socially stratified, and be an expression of social distress and poverty in low income countries; it may also be a easily noticed and communicated symptom of physical illness, irrespective of culture and language; fatigue expressions are commonplace, and do not require a sophisticated vocabulary that perhaps is demanded of psychological experiences. Social and cultural factors may influence the course of an illness (Njoku, et al., 2005); a study in the US showed that African Americans were more likely to cope with fatigue by turning to religion compared with European Americans; denial as a form of coping was more prevalent among Hispanic Americans (Nkoju, et al, 2005). There is insufficient research on how people experience and talk about fatigue, and how they cope with it, especially when it is not obviously related to a physical illness (Karasz \& Mckinley, 2007). These research questions becoming especially pertinent for ethnically diverse populations who are sometimes reported to make use of physical idioms of distress as well as suffering higher rates of some physical illnesses, making reports of fatigue commonplace. Some assert that physical complaints can mask emotional distress, or in a psychoanalytic sense can represent the distress (converted into physical illness) such that it need not be felt; physical accompaniments of emotional distress are actually common in all societies, but the emphasis of such complaints by ethnic minorities, and those of poor socio-economic backgrounds has also led to suggestions that psychosomatic complaints are forms of social protest and re-positioning in the real world using the idiom of physical illness (Kirmayer \& Young, 1998). In relation to fatigue specifically, less is known or researched about its cultural origins or correlates, and how it may represent somatic distress amongst groups of poorer social status (some ethnic groups). Is fatigue readily recruited because it is com- 
mon place and can easily be made use of without immediate sanctions that the sick role might otherwise impose if a more severe illness were diagnosed or suspected.

Given the lack of research on expressions of distress, attributions and coping with fatigue, qualitative methods can be a good place to begin to explore whether illness behaviour for fatigue is patterned by ethnic and cultural influences. Qualitative methods can demonstrate subtle variations in expressions of fatigue and coping, and can be useful for investigating what underlies quantitative patterning by demographic variables (O'Connor \& Nazroo, 2002b). Existing research suggests that in high income countries ethnic minorities may not seek help for fatigue. (Dinos, et al., 2009) .If there are cultural differences in expressions of fatigue, and in causal attributions and coping, these might explain the previous research showing ethnic minorities do not present to specialist services for fatigue.

Therefore, this study aimed to investigate ethnic and cultural influences on fatigue expressions, causal attribution and coping behaviours among the five main ethnic minority groups in England (Bangladeshi, Black Caribbean, Indian, Irish and Pakistani) and among a white British comparison group. These ethnic categories are used in research and national survey work including the national census. They clearly aim to group individuals by a common ancestral origin and migration history, linking this with race and cultural factors. Notions of ethnicity are clearly contested as categories, given there is so much variability of demographic and cultural characteristics within one ethnic group. Nonetheless, ethnic group patterns for illness prevalence and aetiologies are the first stage of investigating what explains these variations: demographic, cultural, socioeconomic, neurophysiological or environmental factors. Furthermore, ethnic patterns often reflect cultural patterning for recent migrants, and where cultural integration is limited.

We were particularly interested to see if expressions of fatigue were culturally informed, whether there were patterns common to an ethnic group, and if some groups reported greater physical (as opposed to mental) fatigue (Thomas, et al., 2006). We were also interested to investigate individual and ethnic group differences in causal attributions and coping behaviours for fatigue. The research made use of an innovative method called "secondary analysis of qualitative data". The study also demonstrates how this method makes efficient and cost-effective use of existing data sets, to ask specific questions, and how it yields valuable new knowledge. We also highlight the strengths and weaknesses of this method to guide other researchers.

\section{Methods}

\section{Sample}

The Ethnic Minority Psychiatric Illness Rates in the Community (EMPIRIC) survey, commissioned by the Department of Health, consisted of two components: a larger, quantitative survey representative of the ethnic populations in the UK, which investigated ethnic differences in mental illness rates (Sproston \& Nazroo, 2002), and a qualitative study of a subsample of respondents investigating cultural and ethnic differences in contexts and experiences of mental illness (O'Connor \& Nazroo, 2002b). The quantitative survey included a total of 4281 participants between the ages of 16 and 74. A sub-sample of 116 respondents who had experienced any form of difficulty or mental distress (a lay notion of this rather than a clinically diagnosed psychiatric disorder) was interviewed for the qualita- tive follow-up study. Respondents were also selected on the basis of a range of characteristics including ethnic group, main language spoken, migration history, age and gender, and the presence and absence of a common mental disorder (anxiety and depression).

\section{Interviews}

The original interviews were all in-depth, interactive and were conducted in respondents' homes. They lasted between half an hour and two hours. A topic guide was used to allow the interviewer to cover key themes and direct an interview that focused on the context of participants' lives, and how this had shaped their experience of mental distress. Key themes included 1) a general introduction, 2) current circumstances, from housing and employment to religion and ethnicity, 3) perception of difficulty and distress, 4) personal experiences of mental distress and 5) coping mechanisms and 6) use of support services. All interviews were recorded and transcribed verbatim. A total of 34 interviews were conducted in languages other than English, mostly in the Bangladeshi group; these were translated and transcribed by the interviewer to minimise any loss of context. Full details of the study design and original analyses can be found in the original report (O'Connor \& Nazroo, 2002b).

\section{Analysis}

In this study, we undertook secondary analysis of qualitative data collected as part of the EMPIRIC study. This is an innovative method that makes efficient use of existing data, and is not as well known about as secondary quantitative data analysis (Corti \& Thompson, 2004; Corti \& Bishop, 2005). The sample used in the present study was selected for inclusion if, in the original charts developed from the transcripts of the original interviews, subjects had expressed fatigue in the widest sense using various terms, analogies, idioms and symptoms. The transcripts of those identified to have fatigue, and the charts from the original study, were subjected to framework content analysis, defined as any "technique for making inferences by objectively and systematically identifying specified characteristics of messages" (Bryman, 2004). The analysis in this paper followed the stages used in the original study (O'Connor \& Nazroo, 2002b). The first stage of analysis involved familiarisation with the transcribed data and identification of emerging issues to inform the development of a thematic framework. The analysis consisted of thematic analysis and constant comparison across subjects, groups of subjects, and those of different ages, genders, and ethnic groups. This comprised an extracting data and constructing a series of thematic matrices or charts, containing the strongly emergent topic headings, in which data from each case was summarised. The charts were stored in spreadsheet format in Microsoft Excel. The charts and then the transcripts were analysed by two researchers, and later a third to resolve any inconsistency.

The research team included investigators who were new to this data, to ensure a critical and unbiased perspective in analysis, as well as senior researchers who were part of the original research team and so they were aware of the field methods, analytic methods, pilot work and the strengths and weaknesses of the original study. This was important in order not to demand too much analysis beyond that which the data might credibly support. The thematic charts allowed for the full range of views and experiences to be compared and contrasted both across and within cases and for patterns and themes to be identified and explored. The final stage involved classificatory and interpretative analysis of the charted data in order to identify 
patterns and explanations. The methods are consistent with a special use of secondary analysis where the aim is to pursue a new conceptual focus and on a subset of the original data (Heaton, 1998).

\section{Results}

Forty-six transcripts (of 116) were found to contain references to fatigue (see Tables 1, 2 for sample characteristics). These references included expressing fatigue (both directly and through analogies), reporting physical symptoms of fatigue, commenting on sleep or energy, and describing a loss of motivation and function.

Fatigue was often accompanied by self-reports of both physical and psychological illnesses in the sample (Table 3) such as diabetes, asthma, hypertension, etc. There were no obvious patterns in self-reports of physical ill-health by gender or ethnicity. Depression was reported across the ethnic groups, both in the past and present tenses. Depression was reported by a higher number of Black Caribbean, Indian and Irish females than males in their respective ethnic groups; altogether 25 individuals (54\%) reported having suffered from depression.
Table 1.

Fatigue reported by respondents in the EMPIRIC study by ethnic group and gender.

\begin{tabular}{ccccc}
\hline Ethnic Group & $\begin{array}{c}\text { Total N (fe- } \\
\text { male:male) }\end{array}$ & \multicolumn{4}{c}{ Fatigue reported (n; (n/N as \%)). } \\
\hline & & Female & Male & Total \\
\hline Bangladeshi & $18(9: 9)$ & 4 & 3 & $\mathbf{7}(39 \%)$ \\
Black Caribbean & $20(11: 9)$ & 6 & 3 & $\mathbf{9}(45 \%)$ \\
Indian & $19(12: 7)$ & 6 & 3 & $\mathbf{9}(47 \%)$ \\
Irish & $21(13: 8)$ & 6 & 2 & $\mathbf{8}(38 \%)$ \\
Pakistani & $19(11: 8)$ & 3 & 2 & $\mathbf{5}(26 \%)$ \\
White British & $19(11: 8)$ & 4 & 4 & $\mathbf{8}(42 \%)$ \\
Total & $\mathbf{1 1 6}(\mathbf{6 7}: 49)$ & $\mathbf{2 9}$ & $\mathbf{1 7}$ & $\mathbf{4 6}(\mathbf{4 0} \%)$ \\
\hline
\end{tabular}

Table 2.

Age and migration by ethnic group of 46 respondents reporting fatigue symptoms.

\begin{tabular}{|c|c|c|c|c|c|c|}
\hline $\begin{array}{l}\text { Ethnic Group } \\
\text { Age }\end{array}$ & Bangladeshi & $\begin{array}{l}\text { Black Carib- } \\
\text { bean }\end{array}$ & Indian & Irish & Pakistani & $\begin{array}{l}\text { White } \\
\text { British }\end{array}$ \\
\hline $25-30$ & 1 & 2 & 1 & 1 & 0 & 1 \\
\hline $31-35$ & 1 & 3 & 0 & 2 & 0 & 2 \\
\hline $36-40$ & 2 & 2 & 4 & 0 & 1 & 1 \\
\hline $41-45$ & 2 & 1 & 2 & 3 & 4 & 2 \\
\hline $46-50$ & 1 & 1 & 2 & 2 & 0 & 2 \\
\hline Migration & \multicolumn{6}{|c|}{ Number of respondents reporting fatigue/ number of respondents in EMPIRIC study } \\
\hline $\begin{array}{l}\text { Born in UK or moved } \\
\text { prior to age } 11\end{array}$ & $3 / 6$ & $8 / 15$ & $5 / 10$ & $8 / 16$ & $0 / 9$ & $8 / 19$ \\
\hline $\begin{array}{l}\text { Moved to UK at age } 11 \\
\text { or later }\end{array}$ & $4 / 12$ & $1 / 6$ & $4 / 9$ & $0 / 5$ & $5 / 10$ & $0 / 0$ \\
\hline
\end{tabular}

Table 3.

Depression \& Physical Illness: Ethnicity in respondents reporting fatigue.

\begin{tabular}{|c|c|c|c|c|}
\hline $\begin{array}{c}\text { Ethnicity } \\
\text { (number of respondents) }\end{array}$ & Depression & $\begin{array}{c}\text { Depression + Physical } \\
\text { Illness }\end{array}$ & Physical Illness only & Neither \\
\hline Indian (9) & 2 & 2 & 3 & 2 \\
\hline Pakistani (5) & 0 & 4 & 1 & 0 \\
\hline Bangladeshi (7) & 1 & 2 & 1 & 3 \\
\hline Black Caribbean (9) & 6 & 1 & 2 & 0 \\
\hline White British (8) & 1 & 1 & 3 & 3 \\
\hline Irish (8) & 2 & 3 & 1 & 2 \\
\hline
\end{tabular}




\section{Expressions of fatigue}

Overall there was little patterning of the expressions of fatigue by ethnic group. Fatigue was conveyed using a variety of terms, analogies, idioms and symptoms, and these are described in detail below. Respondents from all the ethnic groups

(Excepting Black Caribbean) used various metaphors for their fatigue such as comparing oneself to an old person, referring to oneself as a "broken stick" and feeling "continually hungover”. For example, two respondents compared their fatigue to falling into a "trance" or "spell":

"I fall into a spell...it's like when people like yourselves here are talking to me and I just float off. I go into another world."

(Male, 44, Bangladeshi, migrated to GB aged 24, interviewed in Bengali)

"I was lethargic and... I can remember I used to go into sort of trances, you know, for long periods of time."

(Male, 44, Irish, born in GB)

Sleep disturbance

Individuals expressed their fatigue by referring to sleep problems, and this was found in all ethnic groups. Respondents spoke of "broken" and "affected" sleep, "sleeplessness", "insomnia" and the inability to "switch off". One respondent explained how tired she was by saying that she fell asleep as soon as she went to bed, while another described spending his days "battling against sleep". A few respondents also expressed their desire for sleep as means of communicating their fatigue. They used phrases such as "I could just sleep forever at the moment" and "I just wanted to sleep". One individual remembered:

"not wanting to wake up, just feeling kind of tired and wanting to sleep... what I wanted to do was stay in bed all day"

(Male, 36, Indian, born in GB)

Somatic symptoms

Respondents frequently gave examples of their physical limitations when describing their fatigue such as finding it "difficult to get out of bed", having a "limited body" or having to "sit and veg in front of the telly". Respondents sometimes quantified their fatigue by relating it to specific tasks that they felt unable to carry out. For example, they described being "too tired to go out" or being too tired to "keep fit".

Only Pakistani and Bangladeshi groups used idioms of bodily "weakness" to express their fatigue. One Pakistani respondent, who was interviewed in English, referred several times to feeling generally "weak" due to his diabetes, explaining that when his sugar levels dropped he became "weaker". A Bangladeshi respondent described how his "body gets really weak" when he is stressed. Another Bangladeshi respondent linked feeling "weak" directly to her lack of sleep, adding weight to the notion that this term could be used interchangeably with "tired" for these respondents:

"I am becoming weak day by day...[I] don't get enough sleep...I feel sleepy throughout the day”.

(Female, 44, Bangladeshi, migrated to GB aged 2, interviewed in Bengali)

People from Indian, Pakistani and Bangladeshi backgrounds also tended to qualify their feelings of fatigue by describing an accompanying physical symptom or feeling. For example, a Pakistani woman explained that when she gets "really tired" her "body starts to hurt" and she gets "headaches too" and a Bangladeshi woman explained that her "eyelids are so heavy".

Low or no energy

It was only ethnic minority groups that discussed their fatigue in terms of lack of energy. In particular, four respondents made references to "energy" in talking about their fatigue. An
Irish respondent described how his lack of sleep meant that he was "just not feeling as energetic as one might", while a Black Caribbean woman with a history of depression spoke of having "no energy" and wanting to sit around, smoke and drink coffee. Another Black Caribbean respondent remarked: "I've got no energy...it's like I [have] no life to move.” Finally, an Indian respondent explained that he had become tired because he was using his energy "stressfully".

Loss of motivation and "function"

Respondents from Black Caribbean, Irish and White British background alluded to a loss of motivation. In particular, 15 respondents mentioned a loss of motivation and/or function, of which only one was Indian. Black Caribbean, Irish and White British respondents often used the expression "can't be bothered" to convey this loss of motivation. These same ethnic groups also reported losing the ability to "function". A Black Caribbean respondent also described this lost ability to function when she was depressed:

“It took over my life. I couldn't do nothing, couldn't even get in the bath... just used baby wipes, wasn't doing housework, house got really filthy"

(Female, 34, Black Caribbean, born in GB)

\section{Causal Attributions for Fatigue}

Respondents outlined a range of circumstances and experiences that they felt to be the 'cause' of their fatigue. A single cause was rarely given; rather, individuals saw their fatigue as having several origins.

Mental distress and depression

In each ethnic group some respondents attributed their fatigue to mental distress and depression.

Some individuals attributed their tiredness directly to depression, saying that it made them "slow", "lethargic", and "tired physically".

"If I get depressed then I just go into a hole...[I] lock myself away...not wanting to wake up, just feeling and wanting to sleep"

(Male, 36, Indian, born in GB)

Other respondents described an indirect link between fatigue and depression, most commonly through insomnia. Interestingly, it was often the fatigue and the difficulty sleeping that spurred these respondents to seek help, rather than the cognitive symptoms of depression. Respondents also alluded to their loss of motivation when they were depressed:

"I was so depressed [I] didn't want to go outside, $[I]$ just wanted to stay at home"

(Female, 40, Pakistani, migrated to GB aged 26, interviewed in Urdu)

Work-related stress

Working long hours, having trouble at work, disliking one's job and increased workload were all linked to fatigue across the ethnic groups. One Indian respondent attributed her fatigue to taking on a new job where there was a backlog of work to take care of. Two White British respondents spoke in very similar terms of the effects of increased "stress" at work on their sleep.

Work, gender, family

Black Caribbean and Indian female respondents alone attributed their fatigue to the pressures of combining work with a family. For example, a Black Caribbean respondent with three young children spoke of her constant fatigue due to combining full time work with looking after her young children. An Indian respondent described a similar, busy schedule and complained of never finding the time to sit down due to working all day and 
then taking care of her family in the evenings. This same respondent asked rhetorically "Why did God give so much work to women? Less responsibility on men, for all women it's like this?” A Pakistani respondent whose husband had recently suffered a heart attack also complained of feeling "shattered" due to having to work all day and then look after both children and home without her husband's help.

Three South Asian women attributed their fatigue directly to looking after the home and "family responsibilities", without implicating employed work. These responsibilities included housework, laundry, cooking, shopping, going to the post office, getting children ready and looking after visitors. Interestingly, all three women were also full-time carers for their sick husbands: "I look after my sick husband completely...everything I do for him". These women also complained of very busy schedules- "when will I work? I am too busy with my family responsibilities"-and attributed feeling tired to having so many responsibilities.

Injury, illness and medication

Individuals across the ethnic groups attributed their fatigue to an injury or a health-related problem such as childhood meningitis, fibromyalgia, irritable bowel syndrome (IBS) and diabetes. Two Irish and one Black Caribbean respondent attributed their fatigue to the effects of medication for psychotic depression, epilepsy and depression, respectively.

Relationship problems

Four female respondents attributed their insomnia to troubles with their ex-partners. Interestingly, all four women described a fear of staying at home alone as a consequence of their troublesome relationships, and linked this fear to their insomnia.

"[I] felt insecure even about staying at home. Frightened that someone would come and do something to us. Couldn't get to sleep at night because I was frightened"

(Female, 40, Pakistani, moved to GB aged 26, interviewed in Urdu)

Racism

Over half (18/30) of the non-White respondents in this study had experienced racial discrimination, both interpersonal and institutional, at some point in their lives. These experiences of racism were often related to bullying and victimisation as a child and later at work:

"You can't just suddenly forget about it, it got stuck into my brain, his face and his behaviour, everything like a photographic memory keep coming and going, it was like it kept playing to my mind"

(Male, 30, Bangladeshi, moved to GB age 21, interviewed in English and Bengali)

"Somebody just made up their mind they didn't want me there and went out of their way to make it really difficult"

(Female, 29, Indian, born in GB)

One respondent spoke about institutional racism in particular and suggested that he was worn by racism. In particular, the participant reported that he finds institutional racism:

“...worse than being abused on the streets, it's actually very, very tiring"

(Male, 36, Indian, born in GB)

\section{Coping Behaviours for Fatigue}

Respondents outlined the resources they used to help them cope with their fatigue itself, which ranged from visiting their doctors to developing a positive outlook on life. The vast majority described how they had coped with what they saw as the source of their fatigue.

Use of health services
Respondents from all of the ethnic groups reported visiting their GP specifically, though not always exclusively, for their fatigue. They often sought help for insomnia and six respondents reported being prescribed sleeping tablets. Seeking medical help for fatigue was especially common in the Indian group.

Black Caribbean and Irish respondents were more likely to use other formal support services including counsellors, psychotherapists and voluntary groups. These services were widely called upon to assist a wide range of problems, from depression to discrimination in the workplace and troublesome relationships, although respondents reported both positive and negative experiences of these services.

\section{Not Seeking Help}

The vast majority of respondents who reported fatigue did not mention seeking support specifically for their fatigue. This may be because they saw fatigue as part of a larger problem, and that they developed coping strategies for these other problems (see above). However, two other factors may have contributed to not seeking help. Some individuals did not perceive fatigue as a medical problem and normalised it by saying that this "sort of frustration prevail[s] in everyone's life", or that they expected other people in their position to feel tired too. Some respondents were also cynical about service provision because of bad or ineffective past experiences and respondents across the ethnic groups were sceptical about professionals empathising with them, commenting that "they're not in your shoes", "they're not experiencing what you're experiencing" and "they don't understand the real situation".

Support from family and friends

Family and friends were frequently seen as an important source of support for respondents across the ethnic groups. For example, a Pakistani respondent explained how she and her husband would come back from work and "just talk to each other...just to talk, just to take out everything”. A Black Caribbean respondent who suffered from severe depression explained how her foster children were key to her recovery, "because I always felt they had no-one except for me...I had to be there for them".

\section{Keeping busy}

Respondents described coping with fatigue by engaging in many different activities, including watching television, going outside for a walk, hill walking, exercise, artwork, drinking and reading. There was recurring mention of "keeping busy".

"The journey itself helped me to concentrate...I realise now that...the travelling, even though it was making me tired, I was actually focused"

(Male, 26, Black Caribbean, born in GB)

Religion

South Asian respondents were more likely to refer to religion as a coping mechanism than the other ethnic groups. A Bangladeshi respondent was asked how she coped with everyday worries, and she replied "I surrender everything to God. He is the boss". Similarly, other respondents described believing that their future was "in God's hands", and that "everything will be taken care of by him". An Indian respondent described how religion had helped him during stressful times because he had prayed more often: "when something goes wrong you start praying and of course it helps". An Irish respondent echoed this by likening praying to a "mini counselling session".

Outlook and personal resources

Some respondents kept a positive outlook on life and were stoic about their difficulties, using phrases such as "I have to go on”. Others described putting things into perspective and ac- 
cepting difficulties, saying "you have to accept it sometimes" or "I just let it go". A few respondents recalled "keeping things back" and "locking [their] problems in a cupboard" to help them cope. Denial was also noted, mostly where respondents 'normalised' their difficulties. Some individuals adopted a philosophical approach. For example, a Bangladeshi respondent explained that her children were a source of inner strength for her when she was exhausted, as she regained her inner happiness when she saw their faces.

\section{Discussion}

\section{Expressions of Fatigue}

Fatigue was conveyed using a variety of terms, analogies, idioms and symptoms and there were many similarities between the groups. In particular, respondents from all the ethnic groups described their fatigue by giving examples of their physical limitations and qualified their fatigue by referencing their sleep. This is curious given the attention given to differences in the presentation of physical complaints in different ethnic groups. The studies that find these differences tend to reflect professional judgements rather than the experience-near complaints in the language of the subject. It may be that at the individual level of analysis that makes use of lay terms, more similarities are seen; and that it is only at a level of professionalised language or diagnostic process that differences between ethnic groups emerge, not as there are true differences but because the observer makes sense of the observed symptoms and complaints, but only recognising them if they match medical nosology; ethnic minorities may not be as familiar with medical language or popular psychology. This might relate to education, or true differences in explanatory models for illness and distress that makes use of culturally and religiously influenced beliefs about health and well-being.

However, there were also some differences. Although the term "tired" was used by all the ethnic groups, with respondents using phrases such as "I feel tired" and "my whole body is tired", only Pakistani and Bangladeshi informants reported feeling "weak" and expressed their fatigue in terms of bodily "weakness". They were also more likely to report an accompanying physical symptom or sensation in relation to their fatigue. These results suggest that expressions of fatigue were linguistically or culturally influenced rather than being "culture-bound" (Kleinman, 1987). Previous research suggests that ethnic minority groups are more likely to report physical than mental fatigue (Jason, et al., 1999; Thomas, et al., 2006). Although physical fatigue is reported with greater frequency from ethnic minority groups than the British white group, no ethnic differences were found in reports to mental fatigue. However, there was a tendency to emphasise systemic weakness with greater frequency in some minority ethnic groups perhaps reflecting traditional South Asian humoural concepts associated with depleted or weakened blood (Karasz \& Mckinley, 2007). Black Caribbean, Irish and White British respondents were more likely to describe a loss of motivation and "function". This ranged from the inability to go to work to feeling unable to do "anything" such as having a bath and doing housework. Thus different expressions for fatigue may make this more difficult to recognise in some individuals, but want explains previous findings that ethnic minorities do not seek help from health care services.

\section{Causal Attribution and Coping}

\section{Explaining no ethnic differences}

Everyday stressors such as work featured heavily in the discourses of causality in all the ethnic groups, both directly-due to their wearying effects - and indirectly, through their impact on stress 'levels' and, consequently, on sleep. Inter-group differences were mostly seen among female respondents who attributed their fatigue to work, family, the home or a combination of these. It seems that diverse attributions and coping styles for fatigue may well explain not seeking help. Illness attribution can have a considerable impact on the experience of illness (Torres-Harding, et al., 2002; Karasz \& Mckinley, 2007). Most respondents were most likely to attribute their fatigue to psychosocial causes, including depression and mental distress, work-related stress and relationship problems. This is in keeping with other studies that have found low levels of health attributions for fatigue in the community (Pawlikowska, et al., 1994). Indeed only a small number of respondents $(n=7)$ attributed their fatigue to a physical cause such as ill health or injury, either wholly or in part. So the attributions may be similar across ethnic groups, but again perhaps it is coping and help seeking, and subsequent professional recognition and labelling, that differ across ethnic groups.

Explaining some ethnic differences

Some notable differences in both attributions and coping that were related to ethnicity and gender were found. For example, Black Caribbean and Indian women were more likely to attribute their fatigue to the difficult task of combining family life with paid employment. Furthermore, South Asian women tended to attribute their fatigue to a host of "family responsibilities" that were strongly associated with traditional female roles. These responsibilities included looking after their (sick) husbands, doing the housework, getting their children ready and looking after visitors. Black Caribbean, Irish and White British respondents were more likely to attribute their fatigue directly to their children.

Racism was also reported as a cause of fatigue in Bangladeshi and Indian respondents. Thomas, et al. (2006) found that individuals who reported more racial discrimination experienced greater fatigue and had less stage four sleep. A well documented finding is that racism can be an important risk factor for poor health. For example, hypertension, poorer self-rated health status and common mental disorders are all associated with self-reported experiences of racism and unfair treatment (Schulz \& Israel, 2000; Karlsen \& Nazroo, 2002; Bhui, et al., 2005).

So both gender roles and experiences of racism may differ across ethnic groups and could explain different attributions, coping styles, and therefore, help seeking. Indeed, many respondents did not seek health care support for fatigue, either because their attributions were not health related, or they perceived health care professionals to be unhelpful. Normalised attributions of fatigue without explaining their condition as illness may explain poorer help seeking, or service uptake, or that there are miscommunications in medical consultations that overlook fatigue symptoms (Luthra \& Wessely, 2004). The social and normalising attributions, especially if expressed alongside symptoms, may explain this tendency of doctors to not to refer to specialist medical care.

Religious coping was quite common, but only in ethnic minority groups. This is a finding that was also reported in the EMPIRIC study, which found that the Bangladeshi and Caribbean groups made more references to their religious beliefs in 
response to mental distress (O'Connor \& Nazroo, 2002a). The results in this study showed that religion as a coping mechanism featured heavily amongst the Pakistani, Indian and Bangladeshi ethnic groups within the sample. Therefore, religious coping may be used for all forms of distress and worry rather than being a specific way of coping with fatigue.

\section{Depression and Fatigue}

Depression and mental distress were frequently cited as causes of fatigue in our sample. This was not surprising in a context where respondents were selected for interview only after showing some indication of mental distress or some difficulty. However, the attributions of a causal relationship operated in the opposite direction too, with a number of respondents ascribing their depression to fatigue. Studies in both primary and secondary care repeatedly find high levels of co-morbidity between depression and fatigue (Williamson, et al., 2005). It has been suggested that "fatigue is neither purely predictive nor a consequence of psychiatric disturbance" and that it probably represents an "aetiologically heterogeneous" condition (Addington, et al., 2001). In the absence of a past history of depression, it is possible that some respondents did not recognise, understand or experience the cognitive aspects of their depression. If this is the case, and fatigue is a core symptom of depression (WHO, 2004) (Williamson, et al., 2005), fatigue is likely to be given greater diagnostic significance by doctors, Therefore, knowledge and understanding of the range of idioms used to express fatigue in different ethnic groups has important implications for detection, intervention and recovery.

\section{Limitations and methodological innovation}

The approach to secondary qualitative data analysis depends on the quality of the original data, and an understanding by researchers of the risks of decontextualised data collected with another purpose in mind. Although fatigue was expressed by nearly half the EMPIRIC qualitative sample, and many of the original research questions contributed valuable detail to the context of respondents' experience of fatigue, the original interview was not focussed on fatigue. Interviewers were not encouraged to probe deeper if respondents reported fatigue, and questions designed to elicit respondents' views on attribution and coping may have reflected their experience of mental distress, rather than fatigue per se, although the data does not indicate this to be a problem. Furthermore, respondents may have experienced fatigue without the subject arising during the interview.

Our results cannot be statistically generalised to the wider ethnic minority populations, but, given the sample used in the study is purposively drawn to represent key components of the referent populations, the conclusions drawn can be applied to the broader population. However, we are able to assert with confidence the key findings, especially that mental distress and social distress are proposed to be related to fatigue; a strength of our work is that the researchers were experienced in working with the EMPIRIC data and used transparent methods. This approach permitted the research team to critically review the analysis and to ensure that the findings were not a function of the de-contextualisation of the data.

\section{Conclusion}

More research is needed into the effects of medical illness and social adversity, for example, discrimination on fatigue, functioning and depressive illness (Bhui, et al., 2005). The moderating effect of socio-economic status on other minority ethnic groups should also be investigated, as well as other covariates such as sleep and pain (Reyes-Gibby, et al., 2003).

\section{Acknowledgements}

This work was supported by the Medical Research Council in the UK (grant G0500978 to KSB in 2006).

\section{References}

Addington, A. M., Gallo, J. J., Ford, D. E., \& Eaton, W. W. (2001) Epidemiology of unexplained fatigue and major depression in the community: The baltimore ECA follow-up, 1981-1994. Psychological Medicine, 31, 1037-1044. doi:10.1017/S0033291701004214

Bardwell, W. A., Burke, S. C., Thomas, K. S., Carter, C., Weingart, K., \& Dimsdale, J. E. (2006) Fatigue varies by social class in African Americans but not Caucasian Americans. International Journal of Behavioral Medicine, 13, 252-258. doi:10.1207/s15327558ijbm1303_9

Bhui, K., Stansfeld, S., McKenzie, K., Karlsen, S., Nazroo, J., \& Weich, S. (2005) Racial/ethnic discrimination and common mental disorders among workers: findings from the EMPIRIC Study of Ethnic Minority Groups in the United Kingdom. American Journal of Public Health, 95, 496-501. doi:10.2105/AJPH.2003.033274

Bryman, A. (2004) Social research methods. New York: Oxford University Press.

Chalder, T., Berelowitz, G., Pawlikowska, T., Watts, L., Wessely, S., Wright, D., \& Wallace, E. P. (1993) Development of a fatigue scale. Journal of Psychosomatic Research, 37, 147-153. doi:10.1016/0022-3999(93)90081-P

Corti, L., Bishop, L. (2005) Strategies in teaching secondary analysis of qualitative data. Forum for Qualitative Social Research, 6, 47.

Corti, L., \& Thompson, P. (2004) Secondary analysis of archive data. In C. Seale, G. Gobo, J. F. Gubrium, \& Silverman, D. (Eds.), Qualitative research practice (pp. 327-343). London: Sage. doi:10.4135/9781848608191.d26

Dinos, S., Khoshaba, B., Ashby, D., White, P. D., Nazroo, J., Wessely, S., \& Bhui, K. S. (2009) A systematic review of chronic fatigue, its syndromes and ethnicity: Prevalence, severity, co-morbidity and coping. International Journal of Epidemiology, 38, 1554-1570. doi:10.1093/ije/dyp147

Heaton, J. (1998) Secondary analysis of qualitative data. URL: http://sru.soc.surrey.ac.uk/SRU22.html

Jason, L. A., Richman, J. A., Rademaker, A. W., Jordan, K. M., Plioplys, A. V., Taylor, R. R., McCready, W., Huang, C. F., \& Plioplys, S. (1999) A community-based study of chronic fatigue syndrome. Archives of Internal Medicine, 159, 2129-2137. doi:10.1001/archinte.159.18.2129

Karasz, A., \& Mckinley, P. S. (2007) Cultural differences in conceptual models of everyday fatigue: A vignette study. Journal of Health Psychology, 12, 613-626. doi:10.1177/1359105307078168

Karlsen, S., \& Nazroo, J. Y. (2002) Relation between racial discrimination, social class, and health among ethnic minority groups. American Journal of Public Health, 92, 624-631. doi:10.2105/AJPH.92.4.624

Kirmayer L. J., \& Young, A. (1998) Culture and somatization: clinical, epidemiological, and ethnographic perspectives. Psychosomatic Medicine, 60, 420-30.

Kleinman, A. (1987) Anthropology and psychiatry. The role of culture in cross-cultural research on illness. British Journal of Psychiatry, 151, 447-454. doi:10.1192/bjp.151.4.447

Kralik, D., Telford, K., Price, K., \& Koch, T. (2005) Women's experiences of fatigue in chronic illness. Journal of Advanced Nursing, 52, 372-380. doi:10.1111/i.1365-2648.2005.03602.x

Luthra, A., \& Wessely, S. (2004) Unloading the trunk: neurasthenia, CFS and race. Social Science \& Medicine, 58, 2363-2369. doi:10.1016/j.socscimed.2003.08.031

Mears, C. J., Taylor, R. R., Jordan, K. M., \& Binns, H. J. (2004) So- 
ciodemographic and symptom correlates of fatigue in an adolescent primary care sample. Journal of Adolescent Health, 35, 528.e21528.e26.

Njoku, M. G. C., Jason, L. A., \& Torres-Harding, S. R. (2005) The relationships among coping styles and fatigue in an ethnically diverse sample. Ethnicity \& Health, 10, 263-278.

doi:10.1080/13557850500138613

O'Connor, W., \& Nazroo, J. (2002a) Ethnic differences in the context and experience of psychiatric illness: A qualitative study. DH, HM Stationery Office, London.

O'Connor, W., \& Nazroo, J. (2002b) Ethnic differences in the context and experience of psychiatric illness: A qualitative study (EDCEPI). DH, HM Stationery Office, London.

Pawlikowska, T., Chalder, T., Hirsch, S. R., Wallace, P., Wright, D. J. M., \& Wesely, S. C. (1994) Population based study of fatigue and psychological distress. British Medical Journal, 308, 763-766.

Reyes-Gibby, C. C., Mendoza, T. R., Wang, X. S., Anderson, K. O., \&

Cleeland, C. S. (2003) Pain and fatigue in community-dwelling adults. Pain Medicine, 4, 231-237.

doi:10.1046/j.1526-4637.2003.03033.x

Schulz, A., \& Israel, B. (2000) Social inequalities, stressors and self reported health status among African American and white women in the Detroit metropolitan area. Social Science \& Medicine, 51, 1639-1653. doi:10.1016/S0277-9536(00)00084-8

Skapinakis, P., Lewis, G., \& Mavreas, V. (2003) Cross-cultural differences in the epidemiology of unexplained fatigue syndromes in pri- mary care. British Journal of Psychiatry, 182, 205-209. doi:10.1192/bjp.182.3.205

Song, S., Jason, L. A., Taylor, R. R., Torres-Harding, S. R., Helgerson, J., \& Witter, E. (2002) Fatigue severity among African Americans: gender and age interactions. Journal of Black Psychology, 28, 53-65. doi:10.1177/0095798402028001004

Sproston, K., \& Nazroo, J. (2002) Ethnic Minority Psychiatric Illness Rates in the Community (EMPIRIC)—Quantitative report. HMSO, London.

Thomas, K. S., Bardwell, W. A., Ancoli-Israel, S., \& Dimsdale, J. E. (2006) The toll of ethnic discrimination on sleep architecture and fatigue. Health Psychology, 25, 635-642. doi:10.1037/0278-6133.25.5.635

Torres-Harding, S. R., Jason, L. A., \& Taylor, R. R. (2002) Fatigue Severity, Attributions, Medical Utilization, and Symptoms in Persons with Chronic Fatigue. Journal of Behavioral Medicine, 25, 99-113. doi:10.1023/A:1014850819995

WHO (2004) International Statistical Classification of Diseases and Related Health Problems. URL:

http://www.who.int/classifications/icd/en/

Williamson, R. J., Purcell, S., Sterne, A., Wessely, S., Hotopf, M., Farmer, A., \& Sham, P. C. (2005) The relationship of fatigue to mental and physical health in a community sample. Social Psychiatry and Psychiatric Epidemiology, 40, 126-132. doi:10.1007/s00127-005-0858-5 